\title{
Olhar de bebês em desenvolvimento típico: correlações longitudinais encontradas
}

\section{The gaze of babies in typical development: longitudinal correlations}

\author{
Aline Elise Gerbelli Belini ${ }^{1}$, Fernanda Dreux Miranda Fernandes ${ }^{2}$
}

\begin{abstract}
RESUMO
Objetivo: Verificar quais as correlações existentes longitudinalmente entre o foco de olhar de bebês, em situação de interação maternofilial livre, ao longo dos primeiros meses de desenvolvimento. Métodos: Dezessete bebês saudáveis foram filmados por 30 minutos, mensalmente, entre zero e quatro meses de vida, em situações cotidianas com suas mães. As filmagens foram analisadas em intervalos consecutivos de 30 segundos, sendo registrada a presença ou ausência de 11 categorias de observação do olhar (alvos do olhar dos bebês), enquanto estes estavam em estado de alerta. Resultados: Foram encontradas 21 correlações estatisticamente significantes entre as categorias de observação do olhar, sendo 16 positivas $(76,2 \%)$ e cinco negativas $(23,8 \%)$. O momento com maior número de correlações estatisticamente significantes foi na quarta filmagem, e o momento com menor número de correlações estatisticamente significantes foi na segunda filmagem. A correlação estatisticamente significante mais freqüente, encontrada em quatro dos cinco momentos de coleta (80\%), foi entre as categorias "olhar para o rosto da mãe" e "olhar para os olhos da mãe". Conclusões: Os resultados obtidos, à luz das informações existentes sobre o desenvolvimento inicial de jovens crianças, permitem imaginar relações entre suas competências sensoriais, cognitivas, sociais e afetivas e os alvos de seu olhar. $\mathrm{O}$ aprofundamento do tema, com investigações sobre indícios de atenção compartilhada nesta tenra fase, e reflexões sobre os objetos do olhar dos bebês e a saúde de seu desenvolvimento parecem contribuir para o diagnóstico e a prevenção de distúrbios do desenvolvimento.
\end{abstract}

Descritores: Desenvolvimento infantil; Comunicação; Recém-nascido; Lactente; Percepção visual

\section{INTRODUÇÃO}

O olhar pode ser respondido desde os primeiros momentos de contato entre um bebê e o adulto que o recebe afetivamente. $\mathrm{O}$ olhar se estabelece e progressivamente se aprimora. Além de possibilidade sensorial fundamental no desenvolvimento infantil, por permitir apreender o mundo, é importante componente da comunicação não-verbal e pode indicar fases pelas quais o bebê passa enquanto adquire outras habilidades - sensoriais, motoras, sociais, afetivas.

O olhar pode ser concebido como comportamento, sendo

(1) Mestre, Colaboradora do Laboratório de Investigação Fonoaudiológica em Distúrbios do Espectro Autístico do Curso de Fonoaudiologia da Faculdade de Medicina da Universidade de São Paulo - USP - São Paulo (SP), Brasil. (2) Livre-Docente, Professora do Curso de Fonoaudiologia da Faculdade de Medicina da Universidade de São Paulo - USP - São Paulo (SP), Brasil

Trabalho realizado no Laboratório de Investigação Fonoaudiológica em Distúrbios do Espectro Autístico do Curso de Fonoaudiologia da Faculdade de Medicina da Universidade de São Paulo - USP - São Paulo (SP), Brasil, com financiamento da fundação de Amparo à Pesquisa do Estado de São Paulo - FAPESP em forma de Bolsa de Mestrado.

Endereço para correspondência: Aline Elise Gerbelli Belini. R. Mario Fongaro, 181/63, Vila Marlene, São Bernardo do Campo, São Paulo - SP, CEP 09723-530. E-mail: aliluvi@yahoo.com.br

Recebido em: 9/4/2007; Aceito em: 10/8/2007 possível medi-lo e estabelecer paralelismos e oposições correlações - entre suas manifestações.

O objetivo deste trabalho é verificar quais as correlações existentes entre as categorias de observação do olhar manifestas por bebês saudáveis, ao longo de seu desenvolvimento entre zero e quatro meses de vida.

Observações longitudinais de bebês, nos primeiros meses de vida durante trocas face a face com suas mães, são raras. Igualmente pouco frequiente é a investigação dos bebês antes das seis semanas de vida, o que confere ao primeiro mês do desenvolvimento a condição de "inexplorado"(1).

Considerando-se as trocas comunicativas que ocorrem no início da vida, um bom recurso para a microanálise dos processos é o registro em vídeo de situações interativas naturais. As transcrições microanalíticas das trocas comunicativas entre mãe e bebê podem ser feitas em escala de segundos. A análise permite detectar as modificações evolutivas das díades ${ }^{(2)}$. A sensibilidade materna ao bebê pode ser estudada em atividades rotineiras, como o banho ${ }^{(3)}$.

A comunicação não-verbal envolve expressões faciais, aspectos paralingüísticos, postura e movimentos corporais e pode provocar respostas igualmente não-verbais do interlocutor ${ }^{(4)}$. O comportamento não-verbal pode ser categorizado, sendo exemplos de categorias comportamentais 
infantis: vocalizar, chorar, olhar para a mãe, tocar a mãe durante o olhar, pegar objeto ${ }^{(3)}$. $\mathrm{O}$ olhar do bebê também pode ser classificado, sendo exemplos de critérios: olhar direto, olhar desviado, evitar olhar, olhar simultâneo interrompido, olhar simultâneo não interrompido ${ }^{(5)}$.

O olhar não é simplesmente a visão: tem função psíquica no diálogo olho a olho, apoiando a comunicação e constituindo a relação com o Outro. O olhar não se restringe ao acompanhamento ocular, característica maturativa da coordenação visomotora, presente a partir do quarto mês de vida ${ }^{(6)}$. A articulação entre a realidade orgânica do bebê e o olhar dos pais constitui, complexamente, o corpo do bebê. A unidade da imagem corporal originária, necessária para que o bebê se torne sujeito, só pode se formar no olhar do Outro freqüentemente a mãe ${ }^{(7)}$.

$\mathrm{O}$ organismo humano possui mecanismos especializados para detectar veloz e acuradamente, entre vários olhares, aqueles dirigidos aos olhos. Encontra-se, assim, evolutivamente, mais preparado para interações sociais importantes em comparação com outras espécies ${ }^{(8)}$.

O contato olho a olho é extremamente importante na cultura ocidental, constituindo uma modalidade de comunicação visual entre mães, pais e bebês. É freqüentemente acompanhado pela fala ou pelo toque, interferindo no crescimento do apego do bebê com sua mãe. Quando uma mãe tenta engajar o bebê em uma troca olho a olho, o rosto e os olhos do bebê iluminam-se de forma interessada, alternando-se este comportamento ao abaixar dos olhos ou olhar em outra direção, a fim de se recuperar dos olhares intensos, recentemente enviados à mãe $e^{(9)}$.

O contato ocular é fundamental para o sucesso do desenvolvimento social ${ }^{(10)}$. A habilidade no diálogo olho a olho é adquirida pelo bebê, após um período, variável entre horas e meses no desenvolvimento visual normal, em que ocorre certa vacilação do olhar ${ }^{(6)}$. Por volta de um mês de idade, a manutenção do contato ocular serve, para os bebês, como possibilidade de investigar as regiões ao redor dos olhos e o contorno das faces. A partir daí, no curso do desenvolvimento, o olhar permite ao bebê perceber pistas sobre as emoções dos parceiros $^{(1)}$. Ao dirigir o olhar ao rosto humano, os bebês inicialmente examinam seu contorno e depois movem o olhar para os olhos e para a boca. Durante o estado de inatividade alerta, os curtos períodos de atenção visual extasiada podem levar o bebê ao contato olho a olho, momento em que ele e seus pais parecem ser "magneticamente" atraídos à comunicação ${ }^{(11)}$.

Tipicamente, em interações face a face, as mães dirigem olhares brevíssimos a partes do corpo dos bebês e à direção para onde estes olham. As vocalizações dos bebês de quatro a vinte e quatro semanas apresentam relação qualitativa e quantitativa sistemática com o sorriso e com o olhar das mães e com o sorriso e olhar dos próprios bebês, indicando coordenação temporal entre vocalizações e outras ações sociais ${ }^{(12)}$.

Na primeira infância, a atenção ao olhar mútuo tem papel fundamental no estabelecimento de laços com os cuidadores $^{(13)}$. As capacidades: intelectual e interativa do bebê são mais complexas e precoces do que o tradicionalmente defendido. A grande intensidade do primeiro relacionamen- to afetivo do bebê - com sua mãe - é a base fundamental para os próximos relacionamentos ${ }^{(14)}$. Já aos 14 dias de vida, o bebê é capaz de enviar e decodificar unidades não-verbais sutis e de envolver-se em trocas sequienciais relativamente complexas com sua mãe(4).

As expressões faciais do bebê, incluindo o sorriso e o movimento das sobrancelhas, contribuem com o estabelecimento das relações de interação entre mãe e filho. Informações importantes podem ser obtidas observando-se a forma como o bebê se movimenta no colo da mãe, como a segue com cabeça e olhar, como responde à sua voz e à sua forma de segurá-lo ${ }^{(15)}$.

A qualidade da interação precoce entre mãe e criança, retratada pelo comportamento emocional, pelas vocalizações, pelo olhar para a mãe, pela reatividade e pela prontidão para interagir, funciona como recurso para o desenvolvimento diferencial de crianças de risco, conforme indicou pesquisa de seguimento de 347 crianças em risco biológico e psicossocial $^{(16)}$.

Já no último trimestre gestacional, podem-se detectar, no feto, potenciais evocados visuais correlacionados a variações morfológicas cerebrais. Nas primeiras semanas de vida, o recém-nascido apresenta percepção da luz ${ }^{(10)}$. Ao nascimento, o bebê é míope e incapaz de acomodar a visão a distâncias maiores que 20 ou 25 centímetros, sendo que objetos em movimento muito distantes ou muito próximos são vistos como névoas ou manchas ${ }^{(11)}$. Com alguns dias de vida, os bebês não apresentam fixação visual, porém, ainda que com movimentos oculares desorganizados, captam as informações visuais do ambiente. Na primeira semana de vida, os recémnascidos apresentam fixação visual monocular. Ao final do primeiro mês de vida, o bebê volta a face para luz de lanterna. Aos sessenta dias, são detectados os fenômenos de fixação, acomodação, convergência na visão do bebê e inicia-se a habilidade de uso simultâneo dos dois olhos para focar um único alvo e a fusão das duas imagens em uma única percepção. Desde os primeiros estágios do desenvolvimento pósnatal típico, as faces são estímulos bastante salientes ${ }^{(10,17)}$.

Na década de 1960, estudos sobre a fixação visual do neonato detectaram maior tempo de manutenção da atenção visual dirigidos a padrões de contraste claro-escuro e contornos pontudos, mesmo em figuras abstratas. Desde então foi possível identificar as preferências visuais de neonatos de acordo com o direcionamento de seu olhar. Uma bola vermelha posicionada a 20 centímetros da face do bebê provoca movimentação ocular seguida por movimentação cervical horizontalmente e, às vezes, verticalmente. Após poucos minutos, há perda do interesse, porém, quando o bebê encontra-se em inatividade alerta, pode fixar seu olhar em objetos por até dez minutos ${ }^{(11,17)}$.

Entre os dois e três meses de vida, observam-se as coordenações olho-mão e visão-audição; a criança manifesta comportamentos como sorrir ao olhar as próprias mãos e é capaz de alternar olhares entre dois objetos. Entre os três e cinco meses, o bebê apresenta coordenação visão-preensão ${ }^{(17-18)}$.

A visão é o foco motivacional do desenvolvimento do controle de cabeça, sendo que a partir de estímulos visuais e auditivos, os bebês adquirem habilidades motoras providas 
pelos sistemas tátil, sinestésico e vestibular ${ }^{(17)}$. A manutenção da postura de cabeça normal, com face vertical e boca horizontal, atingida por volta dos seis meses, é importante para a comunicação humana, já que o bebê segue o estímulo visual girando sua cabeça. Antes desta idade, a cabeça tende a funcionar como ponto fixo a partir do qual os olhos enxergam o $\operatorname{espaço~}^{(15)}$.

Ainda que o evento observado seja muito significativo (como a forma de olhar da mãe), supõe-se que o esquema perceptual do bebê relacione-se a aspectos comuns ao conjunto de experiências semelhantes (como rostos humanos), originando protótipos esquemáticos. As dimensões do esquema têm determinada saliência em relação ao todo e o tempo de fixação do olhar do bebê depende do tipo de estímulo. A detecção de discrepâncias visuais é possível por volta dos dois ou três meses de idade; isto leva à habituação ou à desabituação visual, que podem ser acompanhadas por mudanças na expressão facial, vocalizações ou movimentação corporal $^{(19)}$.

Durante o quarto mês de vida, os bebês começam a mudar seu foco de atenção da face da mãe para objetos ${ }^{(1)}$. A informação visual à qual os neonatos têm acesso os permite modular a atividade de preensão manual a partir da característica do objeto. Os sistemas visual, vestibular e somatossensorial permitem que o ser humano perceba e participe ativamente do movimento $^{(20)}$. Os objetos tomam relevância e funcionalidade a partir da experiência que os bebês têm com eles. Crianças de quatro meses podem discriminá-los com base em suas diferenças de cor, textura e forma. Antes desta idade, caso as características dos objetos sejam muito complexas, as crianças apresentam maiores dificuldades em segregá-los, devido às ambigüidades espaço-temporais, que as confundem quanto à determinação da individualidade dos objetos $^{(21)}$.

Experimentos com bebês de cinco meses indicaram que quando estes observam pessoas realizando ações repetitivas, a atividade em si adquire papel de "figura" e a face do agente toma valor de "fundo". Ao cessar a atividade, a face, estática, torna-se "figura". Há, portanto, diferenças importantes nas respostas dos bebês, sendo os estímulos dinâmicos mais interessantes em comparação com os estáticos e sendo as ações repetitivas mais salientes do que as faces das pessoas que realizaram tais ações ${ }^{(22)}$. É também possível atentar-se para os aspectos de figura/fundo nas trocas comunicativas ${ }^{(2)}$.

Entre os três e os cinco meses de vida, ou ainda mais cedo, os bebês são capazes de perceber a direção do movimento das pupilas de uma face humana adulta e de seguir a atenção visual do outro, após um período de contato ocular direto $^{(10,23)}$. O seguimento visual é um indicativo de atenção compartilhada e interação social. Aos seis meses, os bebês ainda apresentam dificuldades em reconhecer exatamente o objeto para o qual um parceiro olha, tendendo a fixar seu olhar no primeiro objeto saliente na cena próxima à que chama a atenção de seu par, ou seja, dirigindo o olhar para onde há algo a ser visto. Aos nove meses, o olhar dos bebês segue a direção de suas mães e a habilidade de seguimento visual mostra ótima acurácia apenas aos 18 meses $^{(18,24)}$.

A interação de um bebê com o espelho fornece subsídios para a compreensão da possibilidade de estabelecimento de vínculos e da auto-referenciação a partir da imagem especular desde muito antes do domínio da linguagem. As primeiras interações do bebê com sua imagem são carregadas de aspectos lúdicos, criativos, sendo emocionalmente positi$\operatorname{vas}^{(14)}$. Bebês de três meses sentem-se atraídos pelo contato ocular com suas imagens no espelho, e, dependendo de sua exposição usual ao espelho, diferenciam suas próprias imagens das imagens de outros bebês ${ }^{(25)}$.

\section{MÉTODOS}

Esta pesquisa foi submetida à Comissão de Ética para Pesquisa (CAPPesq Hospital das Clínicas da Faculdade de Medicina da Universidade de São Paulo - HCFMUSP), recebendo aprovação através do parecer número 445/04.

\section{Sujeitos}

Os sujeitos desta pesquisa foram selecionados com base nos seguintes critérios médicos e sociais: ausência de malformações ou síndromes congênitas; peso ao nascimento maior de 2500g; adequação quanto ao crescimento intrauterino; índice ponderal ao nascimento entre os percentiis cinqüienta e noventa; aprovação no rastreamento neonatal para fenilcetonúria; aprovação na triagem auditiva neonatal; ausência de patologias neonatais que impedissem a alta hospitalar no tempo previsto; paridade um ou zero; integração de núcleos familiares completos; pais residentes na Grande São Paulo; consentimento dos responsáveis para realização do estudo através do Termo de Consentimento Livre e Esclarecido aprovado pela CAPPesq.

Trinta e uma famílias foram convidadas a participar deste estudo e a participação de 21 delas foi efetivada, sendo que três bebês foram excluídos da amostra final por não terem completado as cinco sessões de coleta. Dezessete bebês foram sujeitos desta pesquisa. Dez deles $(58,8 \%)$ foram do gênero masculino e sete $(41,17 \%)$ do gênero feminino. Apenas mãe, pai e filho(s) residiam nos domicílios. Todas as famílias pertenciam a classe sócio-econômica-cultural com acesso ao acompanhamento pré-natal e à puericultura. A média de idades das mães dos sujeitos foi de 30,76 anos (entre 20 e 47 anos) e a média de idades dos pais foi de 37 anos (entre 28 e 46 anos). A maioria das mães $(64,70 \%)$ e dos pais $(70,58 \%)$ concluiu o ensino superior. Cinco sujeitos $(29,41 \%)$ tinham irmãos com idades entre dois e cinco anos, sendo $60 \%$ dos irmãos do gênero feminino e $40 \%$ dos irmãos do gênero masculino.

\section{Procedimento}

Contato inicial e protocolo de visita: Os pais dos bebês participantes receberam, no primeiro contato, informações gerais sobre a pesquisa. Os prazos estipulados para a realização das coletas consideraram uma variação de sete dias a partir do início da segunda quinzena de cada mês de vida dos bebês, sendo: F1 (primeira filmagem) - entre o $15^{\circ}$ e o $22^{\circ}$ dias de vida do bebê (DV); F2 (segunda filmagem) - en- 
tre o $45^{\circ}$ e $52^{\circ} \mathrm{DV} ; \mathrm{F} 3$ (terceira filmagem) - entre o $75^{\circ}$ e o $82^{\circ} \mathrm{DV} ; \mathrm{F} 4$ (quarta filmagem) - entre o $105^{\circ}$ e o $112^{\circ} \mathrm{DV}$; F5 (quinta filmagem) - entre o $135^{\circ}$ e o $142^{\circ}$ DV. Para o agendamento das visitas, foram efetuados contatos telefônicos com uma semana de antecedência. Um procedimento piloto possibilitou o teste dos protocolos de visita e de registro dos dados, evidenciando a impossibilidade de registro dos dados em tempo real concomitantemente ao registro por videogravação.

Filmagem: Antes do início da filmagem, a pesquisadora reforçava o caráter natural da coleta, solicitando à mãe que agisse de forma o mais próxima possível à usual e praticasse com o bebê a(s) atividade(s) cotidianamente prevista(s) para aquele momento. As duplas foram filmadas por, ao menos, 30 minutos em cada visita. Foram excluídos os trechos em que o bebê esteve no colo de outra pessoa, exceto a mãe (ocorridos em 1,17\% das filmagens). Durante as gravações, a aproximação e o ângulo de filmagem foram dinamicamente ajustados, objetivando enquadrar sempre que possível os rostos do bebê e da mãe, priorizando-se o rosto do bebê se a opção fosse necessária. Buscou-se enquadrar também o item preciso ao qual o bebê estivesse dirigindo seu olhar, porém mantendo aproximação mínima que propiciasse a nitidez na observação dos olhos do bebê.

Codificação: As filmagens foram assistidas por sujeito e em ordem seqüencial de coleta (F1 a F5). As fitas foram analisadas em intervalos consecutivos de 30 segundos de duração. Cada fita contou com, no mínimo, 60 intervalos.
Cada um dos intervalos foi integral e continuamente assistido, sendo registradas as "categorias de observação do olhar" (COO), ocorridas quando os bebês estavam em estado de alerta (determinado de acordo com os critérios de Brazelton $\left.{ }^{(9)}\right)$. As onze $\mathrm{COO}$ dizem respeito aos focos do olhar dos bebês e foram determinadas para esta pesquisa (o Quadro 1 traz a definição das $\mathrm{COO}$ ).

Para registro das categorias de observação do olhar (COO), levou-se em conta sua presença ou ausência no intervalo. As transcrições foram digitalizadas e analisadas por software especialmente formulado, que contabilizou a freqüência de manifestação de cada categoria de observação do olhar, ou seja, o percentual de intervalos em que ocorreu cada uma das COO, com o bebê em alerta, em relação ao total de intervalos em que o bebê esteve em estado de alerta.

Confiabilidade: Vinte por cento das filmagens foram sorteadas e submetidas à análise por duas juízas, fonoaudiólogas com larga experiência na observação de bebês. Ocorreram sete encontros, sendo o primeiro deles uma sessão de treinamento. Estiveram presentes as juízas e a primeira autora, encarregada da cronometragem e determinação dos intervalos. As juízas assistiram a cada intervalo completo e fizeram seus registros em protocolos individuais. As três primeiras filmagens sorteadas foram utilizadas para compatibilização de análises. Os dados foram submetidos à análise de concordância através do teste estatístico de análise de variância Anova: Fator Único. O p-valor obtido nas comparações entre as três analisadoras indicou concordância em todas as filmagens. Nas

Quadro 1. Categorias de observação do olhar (COO) e suas definições

\begin{tabular}{|c|c|c|}
\hline Sigla & Categoria & Definição \\
\hline OMO & Olhar para os olhos da mãe & $\begin{array}{l}\text { Dirigir o olhar aos olhos ou a um dos olhos da mãe. Olho a olho mútuo, contato ocular } \\
\text { propriamente dito. }\end{array}$ \\
\hline OMR & Olhar para o rosto da mãe & $\begin{array}{l}\text { Dirigir o olhar ao rosto (exceto olhos) ou cabelos da mãe. O comportamento da mãe auxilia } \\
\text { na distinção com o OMO. }\end{array}$ \\
\hline OMC & Olhar para o corpo da mãe & $\begin{array}{l}\text { Fixar ou passar o olhar pelo corpo da mãe: membros, ombros, tronco, mama, mãos. Olhar } \\
\text { para a mãe quando esta está de costas, de lado, ou movimenta-se pelo ambiente, distante } \\
\text { do bebê. }\end{array}$ \\
\hline OAA & Olhar para o ambiente de forma ativa & Olhar vivo, dirigido à cena ambiental. \\
\hline OAP & Olhar para o ambiente de forma passiva & $\begin{array}{l}\text { Olhar "apagado", "perdido" pelo ambiente; não focaliza elementos específicos da cena, } \\
\text { nem a cena em si. }\end{array}$ \\
\hline OJ & Olhar para objeto(s) & $\begin{array}{l}\text { Ativo quando dirigido a objetos pequenos. Pode ser passivo quando dirigido a objetos } \\
\text { grandes. Olhar para peças de vestuário próprias ou da mãe, mesmo que vestidas, quando } \\
\text { atento a suas propriedades físicas. }\end{array}$ \\
\hline OPC & Olhar para o própriocorpo & $\begin{array}{l}\text { Fixar ou passar o olhar pelo próprio corpo (membros ou tronco). Olhar para a própria } \\
\text { imagem no espelho. }\end{array}$ \\
\hline OP & Olhar para a pesquisadora & $\begin{array}{l}\text { Fixar ou passar o olhar pela pesquisadora (corpo ou rosto). Dirigir o olhar à câmera filmadora } \\
\text { ou a seus componentes. }\end{array}$ \\
\hline O० & Olhar para outra pessoa & Dirigir o olhar a quarta pessoa da cena. \\
\hline OF & Olhos fechados & $\begin{array}{l}\text { Fechar os olhos em reação a estímulos externos, internos, à interação materna.Manter os } \\
\text { olhos fechados, incluindo piscada prolongada. }\end{array}$ \\
\hline AFO & Abrir e fechar os olhos & $\begin{array}{l}\text { Piscar os olhos repetidas vezes, como reação a estímulos externos (visuais, auditivos ou } \\
\text { sinestésicos) ou visando defender-se deles. }\end{array}$ \\
\hline
\end{tabular}


amostras para compatibilização, o p-valor variou entre $p=0,61$ e $\mathrm{p}=0,70$. Nas demais amostras, o p-valor esteve sempre entre $\mathrm{p}=0,71$ e $\mathrm{p}=0,99$, com média de $\mathrm{p}=0,93$.

\section{Análise Estatística}

Verificou-se o quão relacionadas estiveram as COOs entre si, aplicando-se a Análise de Correlação de Spearman. O nível de significância adotado foi de $5 \%(\alpha=0,050)$. A partir deste critério, quando a significância calculada foi menor do que $5 \%(\mathrm{p} \leq 0,050)$, encontrou-se uma diferença (ou relação) estatisticamente significante; quando a significância calculada foi igual ou maior do que 5\% ( $\mathrm{p} \geq 0,050)$ encontrou-se uma diferença (ou relação) estatisticamente não-significante, ou seja, uma semelhança. Os coeficientes de correlação positivos indicam comportamentos paralelos entre as viariáveis e coeficientes negativos, comportamentos antiparalelos. Altos coeficientes de correlação (próximos a 1 ou a -1) indicam correlações mais fortes.

\section{RESULTADOS}

Foram encontradas 21 correlações estatisticamente significantes entre as categorias de observação do olhar apresentadas pelos sujeitos ao longo do período estudado, sendo 16 positivas $(76,2 \%)$ e cinco negativas $(23,8 \%)$.

O Quadro 2 apresenta as correlações estatisticamente significantes entre as categorias de observação do olhar em cada um dos momentos de coleta.
As correlações estatisticamente significativas ocorrridas em mais de um momento foram:

a) Positivas: entre as categorias $\mathrm{OMR}$ e OMO, em quatro momentos: F1, F2, F3 e F4; entre as categorias OP e OAA, em dois momentos: F3 e F4.

b) Negativas: entre as categorias $\mathrm{AFO}$ e OJ, em dois momentos: F4 e F5.

Os valores numéricos, por filmagem, encontram-se na Tabela 1.

O momento com maior número de correlações estatisticamente significantes foi a quarta filmagem (F4, sete correlações encontradas). $\mathrm{O}$ momento com menor número de correlações estatisticamente significantes foi a segunda filmagem (F2, apenas uma correlação estatisticamente significante: OMO x OMR).

As correlações mais fortes, por faixa etária, foram: na primeira filmagem (F1), "abrir e fechar os olhos" (AFO) versus "olhar para o rosto da mãe" (OMR); na segunda filmagem (F2), "olhar para os olhos da mãe" (OMO) versus "olhar para o rosto da mãe" (OMR); na terceira filmagem (F3): "olhar para os olhos da mãe" (OMO) versus "olhar para o rosto da mãe" (OMR); na quarta filmagem (F4), "olhar para o próprio corpo" (OPC) versus "olhar para o ambiente de forma ativa" (OAA); na quinta filmagem (F5), "olhar para os olhos da mãe" (OMO) versus "olhar para o rosto da mãe" (OMR).

Foram encontradas correlações estatisticamente significantes em todas as categorias de observação do olhar. As únicas categorias de observação do olhar com correla-

Quadro 2. Correlações estatisticamente significantes entre as categorias de observação do olhar (COO) manifestas em cada momento da coleta

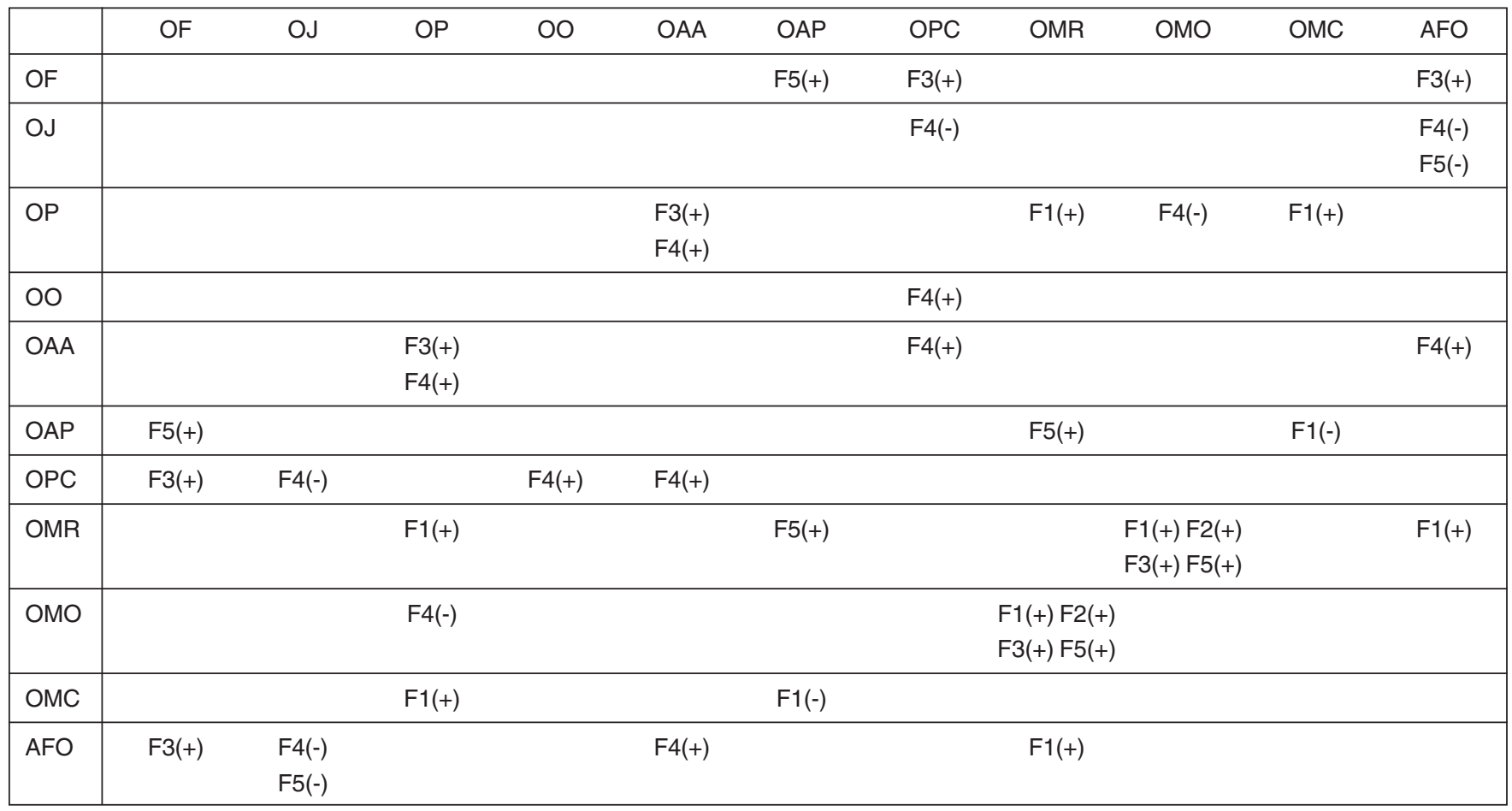

Legenda: OF: "olhos fechados"; OJ: "olhar para objeto(s)"; OP: "olhar para pesquisadora"; OO: "olhar para outra pessoa"; OAA: "olhar para o ambiente de forma ativa"; OAP: "olhar para o ambiente de forma passiva"; OPC: "olhar para o próprio corpo"; OMR: "olhar para o rosto da mãe"; OMO: "olhar para os olhos da mãe"; OMC: "olhar para o corpo da mãe"; AFO: "abrir e fechar os olhos"; F1: primeira filmagem; F2: segunda filmagem/ F3: terceira filmagem; F4: quarta filmagem; F5: quinta filmagem; (+): correlação positiva; (-): correlação negativa. Utilizado Teste de Correlação de Spearman. 
Tabela 1. Correlações significativas entre as categorias de observação do olhar (COO) ao longo dos meses (Análise de Correlação de Spearman)

\begin{tabular}{|c|c|c|c|}
\hline Filmagem & $\begin{array}{c}\text { Par de } \\
\text { variáveis }\end{array}$ & $\begin{array}{c}\text { Coeficiente } \\
\text { de correlação }\end{array}$ & $\begin{array}{c}\text { Nível de } \\
\text { Significância }(p)\end{array}$ \\
\hline \multirow[t]{5}{*}{$\mathrm{F} 1$} & OMR_OP & $+0,502$ & 0,040 \\
\hline & OMC_OP & $+0,505$ & 0,039 \\
\hline & OMC_OAP & $-0,627$ & 0,007 \\
\hline & OMO_OMR & $+0,618$ & 0,008 \\
\hline & AFO_OMR & $+0,706$ & 0,002 \\
\hline F2 & OMO_OMR & $+0,629$ & 0,007 \\
\hline \multirow[t]{4}{*}{ F3 } & OPC_OF & $+0,578$ & 0,015 \\
\hline & AFO_OF & $+0,572$ & 0,016 \\
\hline & OAA_OP & $+0,509$ & 0,037 \\
\hline & OMO_OMR & $+0,736$ & 0,001 \\
\hline \multirow[t]{7}{*}{ F4 } & OPC_OJ & $-0,486$ & 0,048 \\
\hline & AFO_OJ & $-0,589$ & 0,013 \\
\hline & OMO_OP & $-0,492$ & 0,045 \\
\hline & OAA_OP & $+0,672$ & 0,003 \\
\hline & OPC_OO & $+0,490$ & 0,046 \\
\hline & OPC_OAA & $+0,738$ & 0,001 \\
\hline & AFO_OAA & $+0,514$ & 0,035 \\
\hline \multirow[t]{4}{*}{ F5 } & OAP_OF & $+0,568$ & 0,017 \\
\hline & AFO_OJ & $-0,495$ & 0,043 \\
\hline & OMR_OAP & $+0,538$ & 0,026 \\
\hline & OMO_OMR & $+0,857$ & 0,000 \\
\hline
\end{tabular}

Legenda: OMR: "olhar para o rosto da mãe"; OP: "olhar para a pesquisadora"; OMC: "Olhar para o corpo da mãe"; OAP: "olhar para o ambiente de forma passiva"; OMO: "olhar para os olhos da mãe"; AFO: "abrir e fechar os olhos"; OPC: "olhar para o próprio corpo"; OF: "olhos fechados"; OAA: "olhar para o ambiente de forma ativa"; OJ: "olhar para objeto(s)"; OO: "olhar para outra pessoa". Utilizado teste estatístico de correlação de Spearman.

ções existentes em um único momento foram "olhar para outra pessoa" (OO, com "olhar para o próprio corpo" - OPC - em F4) e "olhar para o corpo da mãe" (OMC, com "olhar para a pesquisadora" - OP - e "olhar para o ambiente de forma passiva" - OAP - em F1).

\section{DISCUSSÃO}

Alguns autores trabalham apenas com "olhar para a mãe" sem diferenciá-lo em "rosto", "olho", "corpo"(3,16,26), ou consideram o contato ocular como olhar para a face da mãe ${ }^{(4)}$. As frequientes e fortes correlações entre OMO e OMR, encontradas nesta investigação, valorizam este ponto de vista. Por outro lado, outros resultados ${ }^{(27)}$ indicam a importância da distinção entre as três categorias, já que houve diferenças estatisticamente significantes quanto à freqüência de sua manifestação, na comparação concomitante entre os cinco momentos pesquisados.

O contato ocular (neste trabalho, OMO) é considerado como "olhar mútuo", e poderia ser de grande interesse considerar o olhar das mães ${ }^{(1,12,23)}$, imaginando-se fortes correlações entre o olhar da mãe e o de seu bebê.
Na forma de transcrição adotada nesta pesquisa, observou-se muitas vezes a presença do "olhar para os olhos da mãe" (OMO) e do "olhar para o rosto da mãe" (OMR) no mesmo intervalo de análise, o que provavelmente refletiu-se na existência de correlações positivas entre estas duas categorias de observação do olhar em $80 \%$ dos momentos pesquisados.

Muitas vezes, o contato ocular do bebê ("olhar para os olhos da mãe" - OMO) provocou na mãe maior expressividade, o que pareceu convidar o bebê a olhar para sua boca, que sorria, se movimentava com a fala ou com vocalizações. Assim, registrava-se "olhar para o rosto da mãe" (OMR). Outra possibilidade observada foi a de que, passando o olhar pelo rosto da mãe (OMR), o bebê encontrasse seus olhos (OMO) e fixasse neles seu olhar.

Estatisticamente, dadas as correlações entre tais categorias, há evidências de que o levantamento de uma delas possa suprimir o levantamento da outra. Porém, as descrições da literatura sobre a ausência ou evitar o olhar ${ }^{(1,4,5,9)}$ e ocorrências que os camuflem - os desvios sutis do olhar, o nistagmo, o estrabismo ${ }^{(6-7)}$ ressaltam a delicadeza de equivaler o olhar dirigido ao rosto ou aos olhos da mãe.

Quanto ao "olhar para o corpo da mãe" (OMC), até o segundo mês de vida, os bebês pareceram manifestá-lo especialmente através do olhar para o tronco da mãe, quando deitados em seu colo, como na situação de amamentação. A partir do terceiro mês, pareceram apresentar também o olhar dirigido a partes mais específicas do corpo da mãe, em especial as mãos. Neste momento do desenvolvimento, segundo a literatura, a evolução motora pela qual passa o bebê confere a ele maior autonomia postural ${ }^{(15,19-20)}$.

Isto pode indicar a importância de subdividir a categoria de observação do olhar "olhar para o corpo da mãe" (OMC) em tronco e membros, para estudos específicos das correlações entre tais focos, ou ainda de diferenciar o olhar dirigido à(s) mão(s) da mãe do olhar dirigido ao seu corpo como um todo ${ }^{(17)}$. Tal investigação poderia ser uma idéia para aprofundamento dos estudos relativos ao desenvolvimento visual e social dos bebês.

Reduzindo a gama de focos do olhar englobada na categoria "olhar para o corpo da mãe" (OMC) - ou originando uma nova categoria focada especificamente no tronco da mãe - talvez pudessem ser detectadas correlações positivas entre o "olhar para a(s) mão(s) da mãe" e o "olhar para objeto(s)" (OJ), imaginando-se tais elementos do mundo exterior como "outros" para os quais se olha, no momento em que ocorre o salto de percepção do objeto externo pelos bebês ${ }^{(1,21)}$.

As correlações que envolveram o "olhar para objetos" (OJ) foram sempre negativas - com "olhar para o próprio corpo" (OPC) e com "abrir e fechar os olhos" (AFO), o que indica comportamentos opostos entre estas variáveis. Ainda assim, o "próprio corpo" pode representar um interessante objeto percebido pelo bebê, e pode-se compreender que, enquanto este olhe para tal objeto, deixe de olhar para os demais.

Durante a análise dos dados, observou-se que a maior parte dos olhares do bebê dirigidos ao próprio corpo (OPC) focou-se nas mãos. Isto pode relacionar-se à coordenação 
visomotora e à coordenação mão-visão, dominadas aos quatro meses de vida ${ }^{(6,17-18)}$. Foram encontradas, no presente trabalho, correlações positivas entre o "olhar para o próprio corpo" (OPC) e "olhos fechados" (OF), na terceira filmagem (F3) e entre o OPC e o "olhar para outra pessoa" (OO) e o "olhar para o ambiente de forma ativa" (OAA), na quarta filmagem (F4).

$\mathrm{O}$ olhar para a própria imagem no espelho ${ }^{(14,25)}$ também constituiu "olhar para o próprio corpo" (OPC). A exposição dos sujeitos a esta situação foi rara e não controlada. De qualquer forma, foi observado, no período de coleta, que as mães favoreceram tal tipo de situação quando os bebês tinham a partir de três meses.

Esta pesquisa não considerou se o "olhar para objeto(s)" (OJ) foi decorrente ou não de situações de atenção compartilhada, nas quais, os bebês dirigem seu olhar ao foco de atenção de outra pessoa ${ }^{(8,10,13,23,28)}$. Isto constituiria uma dificuldade para bebês até os seis meses ${ }^{(24)}$, porém, na amostra, pareceu ocorrer algumas vezes, especialmente na quinta filmagem.

Já na primeira filmagem (F1), observou-se que, em situações de aleitamento materno, as mães não mantiveram o olhar obrigatoriamente contínuo aos bebês e que alguns sujeitos apresentaram "olhar ambiente" ("ativo" - OAA ou "passivo" - OAP) durante a mamada. Em F1, o OAP correlacionou-se negativamente ao "olhar para o corpo da mãe" (OMC), indicando oposição comportamental dos sujeitos quanto a tais focos do olhar. Isto pode ser compreendido, já que, ainda o olhar para o corpo da mãe, pode muitas vezes ser passivo nesta fase, e que seu foco dependeria muito da posição em que o bebê é segurado para mamar, do que de sua eleição postural ativa. Especialmente no último momento de coleta (F5), os bebês dirigiram seu olhar para outros focos durante a amamentação e isto chegou a tornar-se uma questão para as mães. Neste momento, o "olhar ambiente passivo" (OAP) esteve correlacionado positivamente às categorias "olhos fechados" (OF) e "olhar para o rosto da mãe" (OMR).

As categorias "olhos fechados" (OF) e "abrir e fechar os olhos" (AFO) parecem indicar o "não-olhar", contraponto do "olhar concretizado", retratado pelas demais categorias. Optou-se por considerá-las, já que a ausência, negação ou evitar o olhar e do contato ocular são dados relevantes quanto à comunicação e ao contato interpessoal, no desenvolvimento humano. Isto levanta questões sobre as várias correlações positivas encontradas entre estes dois tipos de categorias.

Pareceu importante detectar como os bebês se comportam quanto ao fechamento ocular em diversos momentos do desenvolvimento inicial. "Olhos fechados" (OF) é uma categoria sugestiva de interação diminuída ${ }^{(9,11)}$, mas isto não se confirmou, por exemplo, nas situações em que o bebê fechou os olhos ao prever a repetição de ação lúdica da mãe. "Olhos fechados" (OF) foi uma categoria que esteve positivamente correlacionada, na terceira filmagem (F3), a "abrir e fechar os olhos" (AFO) e a "olhar para o próprio corpo" (OPC) e, na quinta filmagem (F5), ao "olhar para o ambiente de forma passiva" (OAP).

Nos momentos inicial e medial de coleta (F1 e F3), "abrir e fechar os olhos" (AFO) apresentou correlações negativas, respectivamente com "olhar para o rosto da mãe" (OMR) e com "olhos fechados" (OF). Nas duas últimas etapas da coleta (F4 e F5), as correlações foram positivas, com as categorias "olhar para o ambiente de forma ativa" (OAA) e "olhar para objetos" (OJ), respectivamente. "Abrir e fechar os olhos" (AFO) foi uma das categorias nas quais as frequiências apresentadas pela amostra, em alerta, foram sempre baixas e não apresentaram diferença estatisticamente significante ao longo do período de coleta $^{(27)}$.

$\mathrm{O}$ "olhar para a pesquisadora" (OP) parece ter significado quanto aos aspectos social e afetivo do desenvolvimento. A correlação positiva encontrada entre as categorias "olhar para a pesquisadora" (OP) e "olhar para o ambiente de forma ativa" (OAA), em dois dos momentos estudados (F3 e F4), pode indicar a importância que o pesquisador (o "outro") tem para o bebê no ambiente para o qual este ativamente olha. No início do desenvolvimento (F1), o OP esteve positivamente correlacionado ao olhar para o "rosto" (OMR) e para o "corpo" da mãe (OMC).

$\mathrm{Na}$ forma de análise adotada, a movimentação ocular do bebê, com passagem para um novo foco de olhar, pôde confirmar a categoria anteriormente apresentada. Este recurso pareceu especialmente importante, no momento da análise, quanto às categorias "olhar para os olhos da mãe" (OMO) e "olhar para o rosto da mãe" (OMR); "olhar para o ambiente de forma ativa" (OAA) e "olhar para a pesquisadora" (OP) e "olhar para o ambiente de forma ativa" (OAA) e "olhar para objeto(s)" (OJ).

Duas destas combinações de categorias - "olhar para o ambiente de forma ativa" (OAA) versus "olhar para a pesquisadora" (OP) e "olhar para os olhos da mãe" (OMO) versus "olhar para o rosto da mãe" (OMR) - apresentaram correlações positivas em mais de um momento.

O conceito de "figura-fundo"(2,22) pode ser pensado nestes casos. No primeiro deles, o bebê, olhando ativamente para o ambiente ("figura") encontra a pesquisadora (OP), que passa a ser "figura", enquanto o ambiente torna-se "fundo". No segundo, quando o bebê apresenta "olhar para o rosto da mãe" (OMR), o rosto da mãe tem valor de "figura", porém quando o bebê foca o olhar em seus olhos (OMO), estes passam a ser "figura" e o rosto da mãe passa a ser o "fundo".

\section{CONCLUSÃO}

O objetivo deste estudo, de investigar as correlações existentes longitudinalmente entre o foco de olhar de bebês, ao longo dos primeiros meses de desenvolvimento, foi atingido por meio do método empregado.

A situação de interação materno-filial livre, na qual os dados foram colhidos, leva a imaginar que o caráter naturalístico das situações é decisivo, intimamente relacionado aos comportamentos indicativos de desenvolvimento do bebê, especialmente pelo fato do interlocutor em questão ser sua mãe.

As 21 correlações encontradas entre as 11 categorias de observação do olhar investigadas, nos cinco momentos 
pesquisados, permitem refletir a respeito de diversas relações entre as competências perceptuais, cognitivas, sociais e emocionais dos bebês, e os focos de seu olhar, neste período inicial de desenvolvimento.

A correlação estatisticamente significante mais freqüente, encontrada entre o "olhar para o rosto da mãe" (OMR) e o "olhar para os olhos da mãe" (OMO), ressalta a importância do contato ocular no desenvolvimento do contato interpessoal e de comunicação da criança.

O aprofundamento deste tema específico e da investigação geral sobre o desenvolvimento infantil nos primeiros meses, possivelmente incluindo investigações sobre indícios de atenção compartilhada, nesta tenra fase e reflexões sobre os objetos do olhar dos bebês e a saúde de seu desenvolvimento, podem contribuir com o diagnóstico precoce e com a prevenção de distúrbios do desenvolvimento.

\begin{abstract}
Purpose: To verify the longitudinal existing correlations between the babies' target of look in the free maternal-filial situation along the first months of development. Methods: Seventeen healthy babies aged between zero and four months of life were monthly videotaped for 30 minutes in daily situations with their mothers. The recordings were analyzed in consecutive intervals of 30 seconds, being registered the presence or absence of eleven categories of observation of the gaze (target of babies gaze), while they were in state of alertness. Results: Twenty one statistically significant correlations were found among the categories of observation of the gaze, being 16 positive $(76.2 \%)$ and five negative $(23.8 \%)$. The moment with the highest number of statistically significant correlations was the fourth recording and the moment with the lowest number of statistically significant correlations was the second recording. The most frequent statistically significant correlation, found in four of five moments $(80 \%)$ was between the categories "look to the mother's face" and "look to the mother's eyes". Conclusions: The obtained results, related to the existing information on the initial development of young children, allow us to imagine relations between their sensorial, cognitive, social and affective competences and their gaze. The deepening of the theme, with investigations on indications of shared attention in this early phase and considerations about the targets of the babies' gaze and the health of their development seem to contribute to the diagnosis and the prevention of the development disorders.
\end{abstract}

Keywords: Child development; Communication; Infant, newborn; Infant; Visual perception

\title{
REFERÊNCIAS
}

1. Lavelli M, Fogel A. Developmental changes in the relationship between the infant's attention and emotion during early face-to-face communication: the 2-month transition. Dev Psychol. 2005;41(1):265-80.

2. Lyra MCDP. Desenvolvimento de um sistema de relações historicamente construído: contribuições da comunicação no início da vida. Psicol Reflex Crit. 2000;13(2):257-68.

3. Silva SSC, Le Pendu Y, Pontes FAR, Dubois M. Sensibilidade materna durante o banho. Psicol Teor Pesqui. 2002;18(3):345-52.

4. Givens DB. Contrasting nonverbal styles in mother-child interaction: examples from a study of child abuse. Semiotica. 1978;24(1-2):33-47.

5. Crown CL, Feldstein S, Jasnow MD, Beebe B, Jaffe J. The cross-modal coordination of interpersonal timing: six-week-olds infants' gaze with adults' vocal behavior. J Psycholinguist Res. 2001;31(1):1-23.

6. Crespin G. Os sinais de sofrimento precoce. In: Crespin G. A clínica precoce: o nascimento do humano. São Paulo: Casa do Psicólogo; 2004. p. 47-76.

7. Laznik MC. Os efeitos da palavra sobre o olhar dos pais, fundados do corpo da criança. In: Wanderley DB, organizadora. Agora eu era o rei: os entraves da prematuridade. Salvador ( BA): Ágalma; 1999. p. 12940.

8. von Grünau M, Anston C. The detection of gaze direction: a stare-inthe-crowd effect. Perception. 1995;24(11):1297-313.

9. Brazelton TB. O bebê: parceiro na interação. In: Brazelton TB, Cramer B, Kreisler L. A dinâmica do bebê. São Paulo: Artes Médicas; 1987. p. 9-23.

10. Farroni T, Johnson MH, Csibra G. Mechanisms of eye gaze perception during infancy. J Cogn Neurosci. 2004;16(8):1320-6.

11. Klaus M, Klaus P. Expressões faciais. In: Klaus M, Klaus P. Surpreendente recém-nascido. Porto Alegre: Artes Médicas; 1989. p. 8396.
12. Hsu HC, Fogel A, Messinger DS. Infant non-distress vocalization during mother-infant face-to-face interaction: factors associated with quantitative and qualitative differences. Infant Behav Dev. 2001;24(1):107-28.

13. Senju A, Yagushi K, Tojo Y, Hasegawa T. Eye contact does not facilitate detection in children with autism. Cognition. 2003;89(1):B43-51.

14. Fiamenghi G. Interações com o espelho: uma análise segundo a teoria da intersubjetividade inata. Temas Desenvolv. 2000;9(50):10-8.

15. Bobath K. Uma base neurofisiológica para o tratamento da paralisia cerebral. São Paulo: Manole; 1982.

16. Laucht M, Esser G, Schmidt MH. Differential development of infants at risk for psychopathology: the moderating role of early maternal responsivity. Dev Med Child Neurol. 2001;43(5):292-300. Comment in: Dev Med Child Neurol. 2001;43(5):291.

17. Alexander R, Boehme R, Cupps B. Normal development of functional motor skills: the first year of life. San Antonio: Therapy Skill Builders; 1993.

18. Deliberato D, Gonçalves VMG. Aspectos do desenvolvimento da percepção visual. Temas Desenvolv. 2003;12(67):5-10.

19. Mussen PH, Conger JJ, Kagan J, Huston AC. Desenvolvimento e personalidade da criança. 3a ed. São Paulo: Harbra; 1995.

20. Rocha NACF, Tudella E. Teorias que embasam a aquisição das habilidades motoras do bebê. Temas Desenvolv. 2003;11(66):5-11.

21. Carey S, Williams T. The role of object recognition in young infants' object segregation. J Exp Child Psychol. 2001;78(1):55-60; discussion 98-106. Comment in: J Exp Child Psychol. 2001;78(1):3-22.

22. Bahrick LE, Gogate LJ, Ruiz I. Attention and memory for faces and actions in infancy: the salience of actions over faces in dynamic events. Child Dev. 2002;73(6):1629-43.

23. Farroni T, Mansfield EM, Lai C, Johnson MH. Infants perceiving and 
acting on the eyes: tests of an evolutionary hypothesis. J Exp Child Psychol. 2003;85(3):199-212.

24. Csibra G, Gergely G. Social learning and social cognition: the case for pedagogy. In: Johnson MH, Munataka Y, editors. Processes of change in brain and cognitive development: attention and performance. Oxford: Oxford University Press; 2005. v.21.

25. Bahrick L, Moss L, Fadil C. Development of visual self-recognition in infancy. Ecol Psychol. 1996;8(3):189-208.
26. Legerstee M, Varghese J. The role of maternal affect mirroring on social expectancies in three-month-old infants. Child Dev. 2001;72(5):1301-13.

27. Gerbelli AE. Desenvolvimento do contato ocular em bebês de zero a quatro meses [tese]. São Paulo: Faculdade de Filosofia Letras e Ciências Humanas da Universidade de São Paulo; 2006.

28. Vlamings PH, Stauder JE, van Son IA, Mottron L. Atypical visual orienting to gaze- and arrow-cues in adults with high functioning autism. J Autism Dev Disord. 2005;35(3):267-77. 